\title{
GEOSPATIAL ESTIMATION OF CHLOROPHYLL-a IN URBAN LAKES
}

\author{
Abdullahi Ahmad Datti*, Sachikanta Nanda, R. Annadurai \\ and Meghna Sengupta \\ Department of Civil engineering, SRM University, Kattankulathur-603203, Tamil Nadu, India \\ *E-mail: abdullahiadatti@gmail.com
}

\begin{abstract}
Water is essential resource for life sustenance especially for drinking, domestic and irrigation purposes. Urban water bodies such as lakes, tanks and ponds plays a vital role in serving their localities as compliment to municipal water supply, irrigation and industrial purpose, controlling runoff and hubs for groundwater recharge. Quality assurance of water resources is mandatory for sustainable water resource management and ensuring compliance with water quality standards. Conventional methods of water quality evaluation are expensive and time consuming; also in situ measurement cannot be carried out in inaccessible areas. For that reason, geospatial technology is applied to evaluate the quality as it provides the required spatial and temporal frequency as well as its synoptic coverage. Chlorophyll- $a$ concentration in water bodies provide the physiochemical property and tropic status of that water. In this study, estimation of Chlorophyll- $a$ has been done from the spectral features extracted from Landsat 8 Operational Land Imager (OLI) data over Kolavai Lake in Kattankulathur Block, Tamil Nadu State, India.
\end{abstract}

Keywords: Chlorophyll- $a$, Water Quality, Landsat 8 OLI, Urban Lakes

(C) RASĀYAN. All rights reserved

\section{INTRODUCTION}

Throughout human history, settlements have been formed and thrived around major rivers and lakes, from the Indus Valley Civilisation around Indus River to Nile Valley Civilisation near the bank of River Nile and the ancient Mesopotamian Civilisation that flourished around River Euphrates-Tigris in the modern day Iraq plus Kuwait, water is central to their growth for its importance in domestic use, agriculture, recreation, aesthetic beauty and influence on local weather and climate. Water is essential and vital for human survival especially for domestic and agricultural purposes in the production of food and animals rearing, it is a resource that needs to be harnessed in a sustainable manner for the benefit of present and future generations. Over the years water quality is deteriorating and the factors responsible are attributed to anthropogenic activities due to increase in population, subsequent urbanization and industrialization which put pressure on water by excessive usage, water bodies encroachment and conversion (usually to built-up lands), dumping of industrial wastes, domestic sewage and unrestrained siltation. These activities results in the obliteration of water and the entire watershed area ${ }^{1}$.

Lakes are water bodies that are completely surrounded by land with no access to ocean or sea. Urban lakes are such lakes that are surrounded by an urban settlement. Lake may be freshwater or salt water lake, shallow or deep, and temporary or permanent. Urban lakes are excellent reservoir of excessive runoff generated from paved urban areas which serves as source of water in the time of its dare need. Water quality is needed as a measure of the physical, chemical, biological, and microbiological characteristics of water. Monitoring water quality provides empirical evidence to support decision making on health and environmental issues. Emphasis is placed on monitoring for compliance with the standard water quality index ${ }^{2}$. Urban lakes unlike their nonurban counterparts are mostly dominated by phytoplankton, dissolved organic matter and other domestic and industrial effluents that are discharged directly on the water or carried by runoff. One of such important biological and physiochemical parameter determining water quality is concentration of Chlorophyll- $a$. 
Chlorophyll- $a(\mathrm{Chl}-a)$ is vital to plants and species of algae like cyanobacteria, it plays an important role in photosynthesis that allows plants to harness energy from the sun. It strongly absorbs electromagnetic radiation in the blue and red wavelength regions and reflects extensively in the green spectrum, this is what made healthy plants to have green colour appearance. Chl- $a$ is water quality parameter that is used extensively for the assessment and monitoring phytoplankton biomass and nutrient status of lakes and other water bodies. The amount of Chl- $a$ concentration can be used to establish a lake's 'trophic' status. Although the trophic status is not associated with any water quality parameter standard, it is an important factor for "rating" the overall productive state of a lake ${ }^{3}$. Chl- $a$ is measured as a way of determining algal (periphyton or phytoplankton) concentration in water. It is expressed as either mass/area for periphyton $\left(\mathrm{mg} / \mathrm{m}^{2}\right)$, or as mass/volume for plankton species $(\mu \mathrm{g} / \mathrm{L})$. An excessive growth of algae in water generally affects water quality and renders it as of substandard quality. Excessive algal concentration may block water filters and irrigation equipment, cause irritating taste and odour in water, lessen dissolved oxygen levels, obstruct fish spawning, degrade macro invertebrate habitat, trap sediment, avert stream flows, and impair the overall aesthetics and recreational value of water ${ }^{4}$.

Currently, in situ water quality parameters measurements and samples collection for subsequent conventional laboratory analyses are used for water quality evaluation. Such measurements may provide the required results for a particular point in time and space, but their major drawback is that they do not furnish either the spatial or temporal view of water quality required for precise assessment and management of lakes ${ }^{3}$. For this reason geospatial technology which utilizes satellite imageries, airborne photographs, imaging spectroscopy and other location-based analytical techniques proves to be effective and efficient in such type of analysis where spatial extent and temporal evaluation are needed. The major advantages of using geospatial approach for water quality parameters estimation is due to its (a) magnificent spatial coverage of satellite imageries into series of scenes covering the globe which allows for synoptic water quality retrieval over large areas, (b) the entire global coverage of satellite imageries permit the estimation of water quality in remote and inaccessible areas, (c) long record of archived satellite imageries (such as Landsat series) made temporal estimation of historical water quality possible at a time when no ground evaluation can be carriedout ${ }^{3}$.

\section{Satellite Data}

\section{EXPERIMENTAL}

Landsat 8 OLI-TIRS (Operational Land Imager-Thermal Infrared Sensor) was utilized in this study. The sensor specifications are given in Table-1 below:

Table-1: Landsat 8 Operational Land Imager (OLI) and Thermal Infrared Sensor (TIRS)

\begin{tabular}{c|c|c|l}
\hline Band & Band Name & Wavelength $(\mu \mathrm{m})$ & \multicolumn{1}{c}{ Area of Usage } \\
\hline 1 & Coastal aerosol & $0.43-0.45$ & Coastal and aerosol analysis \\
\hline 2 & Blue & $0.45-0.51$ & $\begin{array}{l}\text { Bathymetric mapping, it discriminates soil from vegetation } \\
\text { and deciduous from coniferous vegetation }\end{array}$ \\
\hline 3 & Green & $0.53-0.59$ & $\begin{array}{l}\text { Enhances vegetation features and make the band useful for } \\
\text { evaluating plant vigor }\end{array}$ \\
\hline 5 & Red & $0.64-0.67$ & Distinguishes vegetation slopes \\
\hline 6 & $\begin{array}{c}\text { Short-wave Infrared } \\
\text { (SWIR 1) }\end{array}$ & $0.85-0.88$ & Enhances biomass concentration and shorelines \\
\hline 7 & $\begin{array}{c}\text { Short-wave Infrared } \\
\text { (SWIR 2) }\end{array}$ & $2.11-2.29$ & $\begin{array}{l}\text { Enhances the moisture content of soil and vegetation as } \\
\text { well as capability of penetrating thin cloud }\end{array}$ \\
\hline 8 & Panchromatic & $0.50-0.68$ & Improved spatial resolution (15m) for sharper images \\
\hline 9 & Cirrus & $1.36-1.38$ & Enhanced retrieval of cirrus cloud contamination \\
\hline 10 & TIRS 1 & $10.60-11.19$ & $\begin{array}{l}\text { 100m spatial resolution for thermal mapping and } \\
\text { estimation of soil moisture content }\end{array}$ \\
\hline 11 & TIRS 2 & $11.5-12.51$ & $\begin{array}{l}\text { 100m spatial resolution for improved thermal mapping and } \\
\text { estimation of soil moisture content }\end{array}$ \\
\hline
\end{tabular}

*All other bands are $30 \mathrm{~m}$ resolution with 16 days repeat cycle (Source: $\mathrm{USGS}^{2}$ ) 


\section{Study Area}

Kolavai Lake is located in Chengalpet Taluk close to Pulikkam village, Kancheepuram District, Tamil Nadu State, India. It is located between longitude $79^{\circ} 58^{\prime} 40.235^{\prime \prime} \mathrm{E}$ and $80^{\circ} 0^{\prime} 690^{\prime \prime} \mathrm{E}$ and latitude $12^{\circ} 41^{\prime} 18.003^{\prime \prime} \mathrm{N}$ and $12^{\circ} 43^{\prime} 25.749^{\prime \prime} \mathrm{N}$ (figure 1). It is one of the largest lakes located in that area having an aerial extent of 894 hectares serving about 12 villages, ${ }^{6}$ it is very good fishing ground and it provides water for industrial purposes.

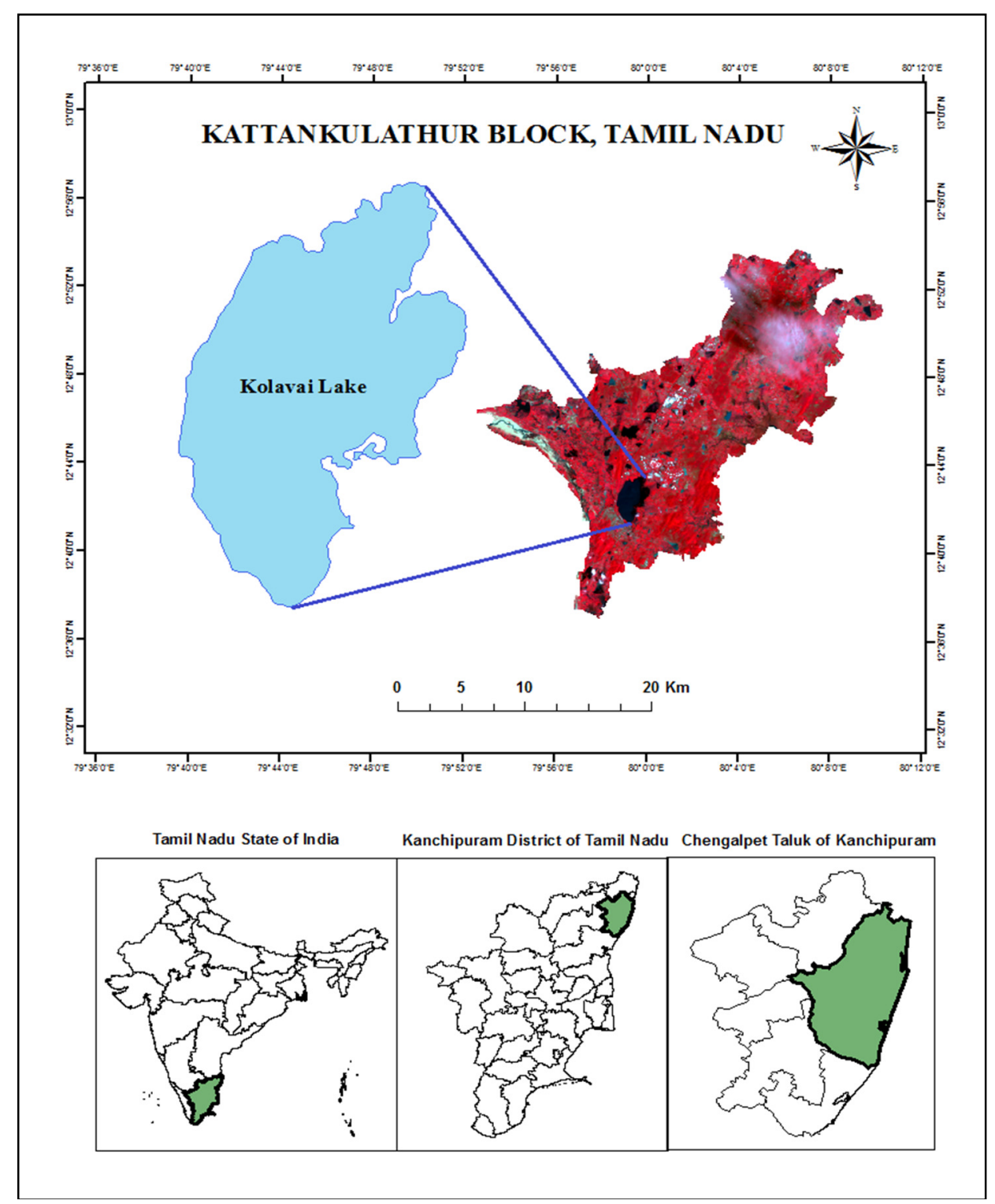

Fig.-1: Map of the study area (Source: USGS, GIS Diva)

The storage capacity of the lake is around 476.69 mcft annually, with a depth of 4.59 meters. The discharging capacity is around 5131 cusecs through by 5 sluices. The excess water discharge by the lake flows into rivers Palar, Neenjal and Madura. Daily, about $200 \mathrm{Kgs}$ of fish are harvested; The Mahindra World City industrial park located near the lake draw5 million gallons of water from this lake daily for their activities. Kolavai Lake is experiencing pollution problem through discharge of agricultural wastes, domestic sewage, hospital wastes and industrial effluents. Chengalpet with a population of $62,579^{5}$ according to 2011 census dumps their garbage in most of the stations located near the lake which can be washed away during the rainy season into the lake and causes severe pollution problem ${ }^{6}$. 


\begin{abstract}
Algorithms
Many spectral combinations and transformation of algorithms and wavelengths (generally called spectral indices) are used to retrieve Chl- $a$ from the satellite imageries' spectral reflectance values of water in oceans, estuaries and inland fresh water. Geospatial estimations of Chl- $a$ is based on observed significant relationships between reflectance values in hyperspectral or multispectral bands or band ratios and chl- $a^{7}$. These algorithms for the estimation of Chl- $a$ concentration in water were developed and demonstrated with both hyperspectral and multispectral data from various satellite sensors such as IRS-1C ${ }^{8}$, MERIS ${ }^{9}$, MODIS $^{10}$, and OCM- $2^{11-12}$. One of the most important remote sensing algorithms for Chl- $a$ estimation is simple band ratio method. Various ratio methods were suggested by several researchers among which are:
\end{abstract}

\title{
Mathias et al (2005) ${ }^{13}$ and Ruddick et al (2001) ${ }^{14}$
}

They found that the best result for Chl- $a$ estimation using hyperspectral data was obtained using the ratio (702/672). The tuned equation used to obtain the Chl- $a$ content was;

\section{Shafique et al (2003) ${ }^{15}$}

$$
\text { Chlorophyll }-a=452.88 \times \operatorname{In} \frac{R 702}{R 672}+4.5279
$$

They proposed the following equation to estimate Chl- $a$;

\section{Gitelson (1992) $)^{16}$}

$$
\text { Chlorophyll }-a=48.849 \times\left(\frac{R 705}{R 675}\right)-34.876
$$

He proposed advanced version of two bands and three bands algorithm using MERIS NIR-Red data. The algorithms are:

Cheng et al (2013) ${ }^{17}$

$$
\begin{aligned}
& \text { Chlorophyll }-a=\left[35.75 \times\left(\frac{R 708}{R 665}\right)-19.3\right] \\
& \text { Chlorophyll }-a=[113.36 \times\{(R 753 /(R 665-R 708)\}+16.4519]
\end{aligned}
$$

Cheng et al (2013) studied the above methods and the equations used after band tuning are;

\section{Zhou et al (2013) ${ }^{18}$}

$$
\begin{aligned}
& \text { Chlorophyll }-a=2805.19 \times\left(\frac{1}{R 677}-\frac{1}{R 680}\right) \times R 670+13.13 \\
& \text { Chlorophyll }-a=-328.60 \times\left(\frac{1}{R 661}-\frac{1}{R 689}\right) \times\left(\frac{1}{R 748}-\frac{1}{R 706}\right)+17.77
\end{aligned}
$$

Zhou suggested these equations for estimating Chl- $a$ concentration;

\section{Zhang and Han (2015) ${ }^{19}$}

$$
\begin{aligned}
& \text { Chlorophyll }-a=624.61 \times\left(\frac{1}{R 651}-\frac{1}{R 691}\right) \times R 754+13.13 \\
& \text { Chlorophyll }-a=130 \times\left(\frac{1}{R 652}-\frac{1}{R 692}\right) \times\left(\frac{1}{R 751}-\frac{1}{R 726}\right)+17.77
\end{aligned}
$$

Since all of the above mentioned algorithms were developed for hyperspectral data, Zhang and Han (2015) suggested the following equation for Landsat 8 OLI multispectral sensor;

$$
\text { Chlorophyll }-a=-0.006 \times 0 L I 2+0.013 \times 0 L I 3+0.003 \times 0 L I 4-0.168
$$

\section{Conversion of DN (digital numbers) to Reflectance}

The DN of Landsat 8 OLI-TIRS was converted to reflectance values using the following equation as provided in the Landsat 8 data handbook available in United States Geological Survey (USGS) website ${ }^{2}$;

$$
\rho \lambda^{\prime}=M \rho Q c a l+A \rho
$$


Where:

$\rho \lambda^{\prime}=$ TOA planetary reflectance, without correction for solar angle

$M_{\rho}=$ Multiplicative rescaling factor

$A_{\rho}=$ Additive rescaling factor

$Q_{c a l}=$ Quantized and calibrated standard product pixel values (DN)

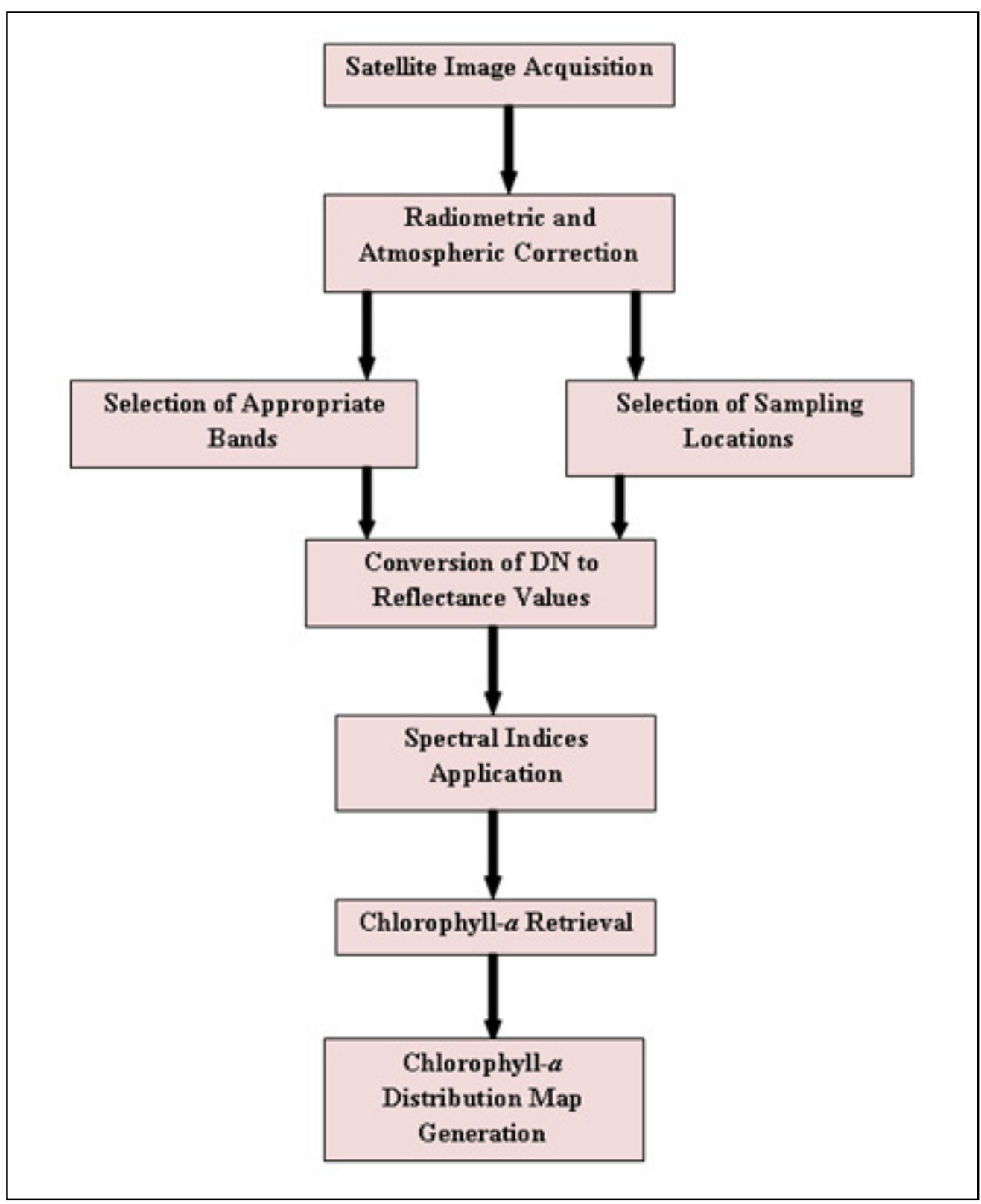

Fig.-2: Methodology Flowchart

\section{Software Utilized}
a. ArcGIS 9.3
b. ENVI IDL 4.3
c. Ms Excel 2007

\section{RESULTS AND DISCUSSION}

Landsat 8 data with scene ID LC81420512016274LGN00 and scene path 142 and row 51 acquired on September 30, 2016 was downloaded from USGS website ${ }^{2}$. The image has been geometrically corrected, 
RASĀYAN $J$. Chem.

Vol. 10 | No. 1 |263 -270 | January - March | 2017

however the DN has been converted to TOA (Top of Atmosphere) reflectance values using equation [10] ${ }^{2}$ on ArcGIS environment. Ten sampling locations were selected across Kolavai Lake and the Chl- $a$ concentration was estimated using model provided by Zhan and Han (2015) ${ }^{17}$ as shown in equation [9] ${ }^{17}$. The result obtained is shown in Table-2.The Chl- $a$ values estimated were then interpolated using inverse distance weight (IDW) technique to generate Chl- $a$ distribution map (Figure-3).

Table-2: Chlorophyll- $a$ values estimated in Kolavai Lake

\begin{tabular}{c|c|c|c}
\hline Sampling ID & Longitude & Latitude & Estimated Chl- $a(\mu \mathrm{g} / \mathrm{L})$ \\
\hline 1 & $79^{\circ} 59^{\prime} 5.393 " \mathrm{E}$ & $12^{\circ} 42^{\prime} 41.047 " \mathrm{~N}$ & 28.02 \\
\hline 2 & $79^{\circ} 58^{\prime} 57.648^{\prime \prime} \mathrm{E}$ & $12^{\circ} 42^{\prime} 3.554^{\prime \prime} \mathrm{N}$ & 27.70 \\
\hline 3 & $79^{\circ} 59^{\prime} 17.87 " \mathrm{E}$ & $12^{\circ} 42^{\prime} 13.966^{\prime \prime} \mathrm{N}$ & 27.81 \\
\hline 4 & $79^{\circ} 59^{\prime} 6.447 " \mathrm{E}$ & $12^{\circ} 42^{\prime} 40.792^{\prime \prime} \mathrm{N}$ & 27.43 \\
\hline 5 & $79^{\circ} 59^{\prime} 31.634^{\prime \prime} \mathrm{E}$ & $12^{\circ} 43^{\prime} 0.524^{\prime \prime} \mathrm{N}$ & 27.53 \\
\hline 6 & $79^{\circ} 59^{\prime} 46.568^{\prime \prime} \mathrm{E}$ & $12^{\circ} 43^{\prime} 17.375^{\prime \prime} \mathrm{N}$ & 24.18 \\
\hline 7 & $79^{\circ} 59^{\prime} 59.324^{\prime \prime} \mathrm{E}$ & $12^{\circ} 42^{\prime} 45.902^{\prime \prime} \mathrm{N}$ & 24.69 \\
\hline 8 & $79^{\circ} 59^{\prime} 46.785^{\prime \prime} \mathrm{E}$ & $12^{\circ} 42^{\prime} 22.085^{\prime \prime} \mathrm{N}$ & 23.55 \\
\hline 9 & $79^{\circ} 59^{\prime} 28.569^{\prime \prime} \mathrm{E}$ & $12^{\circ} 42^{\prime} 36.743 " \mathrm{~N}$ & 27.65 \\
\hline 10 & $79^{\circ} 58^{\prime} 49.404^{\prime \prime} \mathrm{E}$ & $12^{\circ} 42^{\prime} 24.967 " \mathrm{~N}$ & 27.85 \\
\hline
\end{tabular}

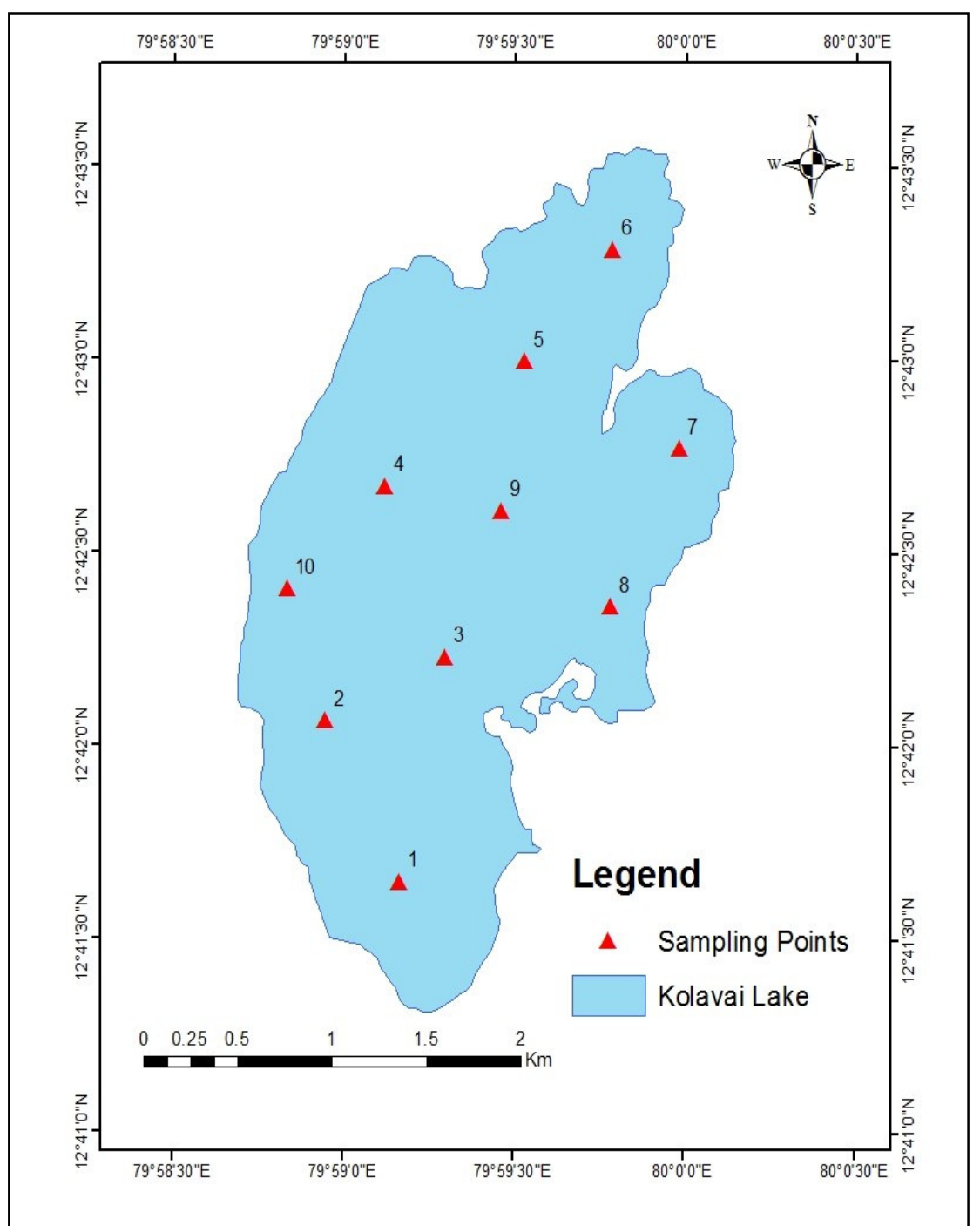

Fig.-3: Sampling Locations in Kolavai Lake 
RASĀYAN J. Chem.

Vol. 10 | No. 1 |263 -270 | January - March | 2017

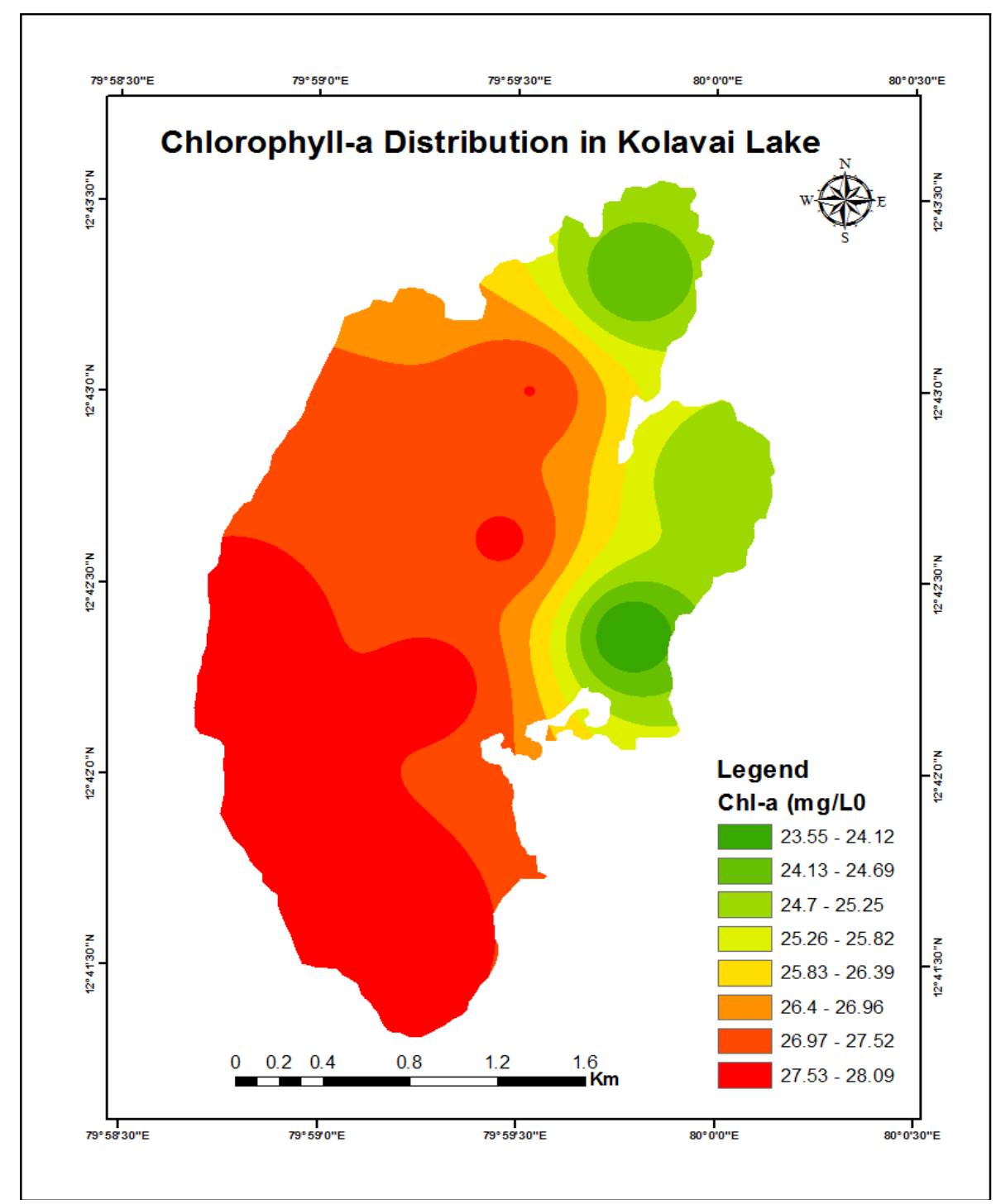

Fig.-4: Chlorophyll- $a$ Distribution Map of Kolavai Lake

Regression analysis was applied to the reflectance values of OLI band 2, 3 and 4 to find their correlation with the estimated Chl- $a$ concentration and they all showed strong relationship as shown in the models in Figures-5 (a), (b) and (c).
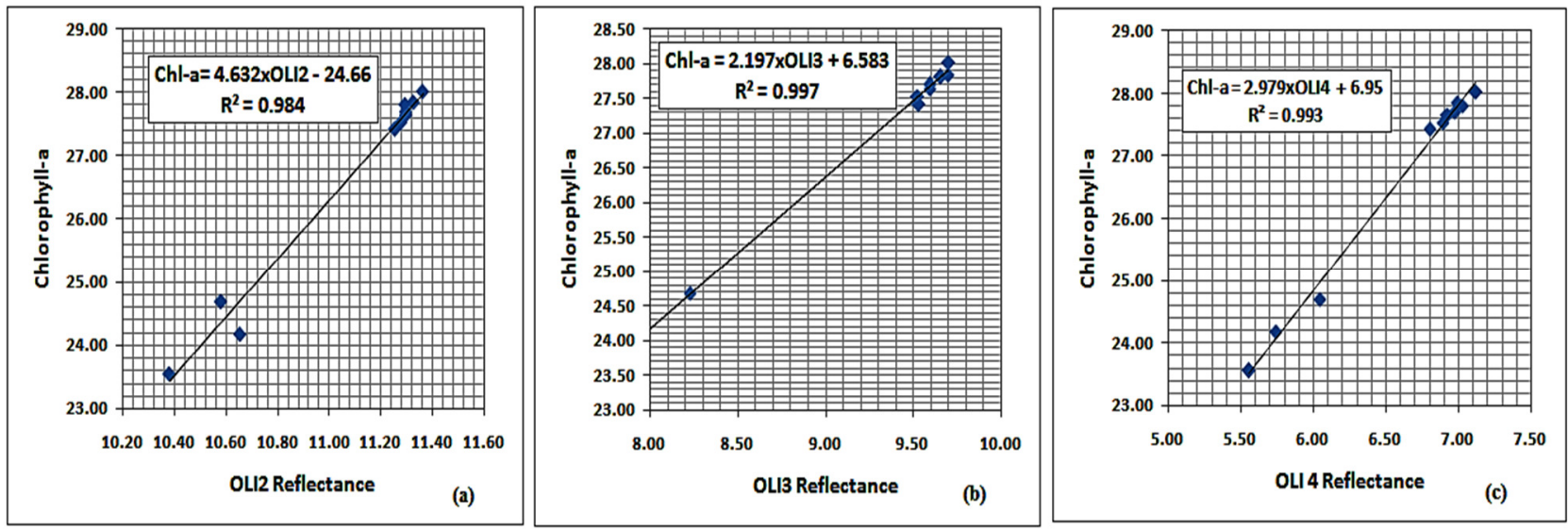

Fig.-5 (a), (b) and (c): Regression model of Chl- $a$ and reflectance values of OLI band 2, 3 and 4 respectively 


\section{CONCLUSION}

This paper demonstrates the Chl- $a$ estimation procedure in urban lakes from using geospatial approach by means of Landsat 8 OLI (Operational Land Imager) satellite sensor data in Kolavai Lake, Kattankulathur Block, Tamil Nadu, India. The study was conducted after monsoon season, the results obtained indicated that the distribution of Chl- $a$ is almost uniform all over the lake surface and are within the acceptable limits of water quality index. Further studies can focus on temporal variation of Chl- $a$ in the lake to assess the rate, pattern and the factors responsible for increase or decrease in Chl- $a$ values. Geospatial approach of Chl- $a$ estimation in urban lakes is cheaper, easier and can provide overall spatial extent and temporal information about the water body under study.

\section{ACKNOWLEDGEMENT}

The corresponding author acknowledges the Government and people of Kano State of Nigeria for providing scholarship grant to study at SRM University and the sponsor of this research project.

\section{REFERENCES}

1. Centre for Science and Environment (2015), "Training on Urban Lake Management - Towards Water and environment Sustainability" September 21-23, 2015, New Delhi, India.

2. United State Geological Survey, "Why Monitor Water Quality?" Water Quality Basics. (2015), available on http://www.usgs.gov/owq

3. A. Kulkarni, Procedia Computer Science, 6, 475 (2011).

4. J. C. Ritchie, M. C. Cooper and F. R. Schiebe, Remote Sensing Environment,33, 137 (1990).

5. Census of India, District Census Handbook Kancheepuram, Directorate of Census Operations Tamil Nadu, (2011).

6. B. K. Ramesh and M. Selvanayagam, International Journal of Chemical Concepts, 1(1), 15 (2015).

7. P. Murugan, R. Sivakumar and R. Pandiyan, ISRS Proceedings, 2014, 536, (2014).

8. S. Thiemann, and H. Kaufmann, Remote Sensing of Environment, 73(2), 227, (2000).

9. W. J. Moses, A. Anatoly, Gitelson, S.Berdnikov, V.Saprygin and V.Povazhnyi, Remote Sensing of Environment, 121, 118 (2012)

10. A. El-Alem, K. Chokmani, I. Laurion and E. S. El-Adlouni, Remote Sens.,4, 2373 (2012).

11. R. Shanthi, D. Poornima, S. Raja, G. V.Sethubathi, T. Thangaradjou, T. Balasubramanian, K. N. Babu and A. K. Shukla,Journal of Earth System Science, 122(2) 479 (2013).

12. T. P. Latha, P. V. Nagamani, K. H. Rao, S. K. Dash, S. B. Choudhury, Aziz Rehman and V. V. S. S. Sarma, J. Indian Soc. Remote Sensing,42(1) 129 (2014).

13. K. Mathias, "Determination of water quality parameters in Indian ponds using remote sensing methods" EARSel 4th Workshop on Imaging Spectroscopy, Warsaw, Poland, (2005).

14. K. G. Ruddick, J. Herman, M. Rijkeboer, and G. Tilstone, Applied Optics,40(21), 3575 (2001).

15. N. A. Shafique, F. Florence, C. A. Bradley and F. Joseph, First Interagency Conference on Research in the Watersheds, (2003).

16. A. Gitelson, Int. J. Remote Sensing, 13(17), 3367(1992).

17. C. Cheng, Y. Wei, G. Lv, and Z. Yuan., Journal of Applied Remote Sensing, 7, (2013).

18. L. Zhou, B. Xu, W. Ma, B. Zhao, L. Li and H. Huai, Water,5, 525 (2013).

19. C. Zhang and M. Han, E-proceedings of the 36th IAHR World Congress, 28 June-3 July, 2015, The Hague, The Netherlands, (2015).

[RJC-1589/2017] 